\title{
Dexmedetomidine Infusion for Prevention of Emergence Agitation after Nasal Surgery
}

\author{
Ramesh Kumar N. ${ }^{1}$ \\ ${ }^{1}$ Department of Anaesthesiology, Sambhram Medical College, KGF, Kolar, Karnataka, India.
}

\section{ABSTRACT}

\section{BACKGROUND}

Emergence agitation is a clinical phenomenon occurring in the immediate postoperative period characterised by agitation, hyperactivity and restlessness. It can lead to various complications ranging from mere injury to cardiac arrest. The objective of the present study was to evaluate the efficacy of intra-operative dexmedetomidine infusion in preventing emergence agitation in adults undergoing nasal surgery.

\section{METHODS}

After obtaining ethical clearance and patient consent, patients undergoing elective nasal surgery under general anaesthesia with ASA 1 and 2 between 20 to 60 years were included in this randomised placebo-control study. Sample size of 100 patients was generated with $80 \%$ power and $95 \%$ confidence interval. Group D $(n=50)$ received dexmedetomidine infusion at a rate of $0.4 \mathrm{mcg} / \mathrm{Kg} / \mathrm{hr}$., from beginning of induction of anaesthesia until extubation and group $C(n=50)$ received volume matched normal saline infusion as placebo. Anaesthesia was maintained with desflurane, and intraoperative haemodynamics and opioid requirement were noted. Ricker sedation-agitation scale was used for assessment of emergence agitation (score $\geq 5$ ). Statistical analysis was conducted using SPSS 15.0.

\section{RESULTS}

All demographic data were comparable between the two groups. Agitation score $\geq 5$ was seen in $4 \%$ and $58 \%$ in group D and group C respectively, and was statistically significant $(\mathrm{p}<0.05)$. Time to verbal response was more in the dexmedetomidine group $(6.74 \pm 2.13 \mathrm{~min} v / \mathrm{s} 5.78 \pm 1.91 \mathrm{~min}, \mathrm{p}<0.05)$; however, no statistically significant difference was noted between the two groups with respect to time to extubation, and duration of PACU stay. Intraoperative fentanyl requirement was more in group C compared to group D.

\section{CONCLUSIONS}

Dexmedetomidine as an infusion of $0.4 \mathrm{mcg} / \mathrm{Kg} / \mathrm{hr}$. from induction till extubation reduces emergence agitation in adults undergoing nasal surgery under desflurane general anaesthesia.

\section{KEY WORDS}

Emergence Agitation, Dexmedetomidine, Nasal Surgery
Corresponding Author: Dr. Ramesh Kumar N., A-1, No. 25, Ashriwad Residency, $R M V, 2^{\text {nd }}$ Stage, Lottegollahalli, New Ramaiah Compound, Bangalore-94, Karnataka, India. E-mail: rameshnareppa@gmail.com

DOI: $10.14260 / j e m d s / 2020 / 182$

Financial or Other Competing Interests: None.

How to Cite This Article:

Kumar RN. Dexmedetomidine infusion for prevention of emergence agitation after nasal surgery. J. Evolution Med. Dent. Sci. 2020;9(11):844-850, DOI: $10.14260 /$ jemds/2020/182

Submission 05-08-2019, Peer Review 19-02-2020, Acceptance 26-02-2020, Published 16-03-2020.

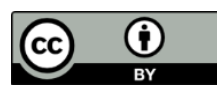




\section{BACKGROUND}

Emergence agitation, also known as emergence excitement, emergence delirium or post anaesthetic excitement is a wellrecognized clinical phenomenon occurring in the immediate postoperative period following general anaesthesia. ${ }^{1}$ Though it is most often seen in children and elderly, 2,3 with literature focused on this population, it can affect all age groups. Emergence is the transition from unconsciousness to full wakefulness ${ }^{4}$ and most often this transition from general anaesthesia is smooth and uneventful. ${ }^{5}$ Emergence agitation is usually seen during the first 15-30 minutes following awakening from general anaesthesia ${ }^{3,6}$ and has varied clinical presentation. It can be characterized by agitation, restlessness, hyperactivity, irritability, thrashing, crying, moaning, incoherence and uncooperative behaviour. $3,4,6$

Though emergence agitation is well recognized clinically, it is not well understood. The reasons being, lack of clear definition, lack of reliable and valid assessment tools, difficulty in differentiating between agitation and pain and uncertainty about its clinical significance. ${ }^{2}$ The incidence reported in paediatric population is $12-13 \%^{3}$ and about $10-15 \%$ in geriatric age group.7,8 There are various risk factors recognized to be associated with EA. They are presence of an endotracheal tube or urinary catheter, pain, premedication with benzodiazepine, use of inhalational anaesthetics, ${ }^{3,5}$ breast, abdominal ${ }^{9}$ and otolaryngologic surgeries. ${ }^{10,11}$ Presence of hypoxia, hypothermia, hypoglycaemia, electrolyte disturbances and sepsis can in addition add on to the incidence of EA. ${ }^{3,5}$

Emergence agitation can lead to various complications like self- extubation, removal of catheters, drains or dressings, aspiration pneumonia, bleeding, need for re-exploration, patients may experience hypertension and tachycardia and lengthens the recovery room stay.2,12,13 An agitated patient can not only inflict injury upon himself but the PACU staff are also at risk of injury.2,12 Additional manpower is required to restrain a patient experiencing EA. It necessitates constant supervision by the PACU nurse, thus impacting their ability to care for other patients in PACU. ${ }^{2}$ It can increase the healthcare costs as it necessitates an increase in pharmaceuticals, staff and increased length of PACU stay. 3,12

Among the various surgeries, otolaryngologic procedures are associated with a higher incidence of agitation.9,10,11 It is speculated that these patients may have a sense of suffocation ${ }^{9}$ during emergence from anaesthesia due to the presence of nasal packing, thus increasing the incidence of agitation. As emergence agitation is costly in terms of morbidity, longer PACU stay, human resources and pharmaceuticals required, ${ }^{12}$ it is essential to prevent this phenomenon and provide a smooth and uneventful emergence. Various modalities have been employed to prevent or treat EA. Identifying and eliminating the precipitating factors if possible is the most important among them. Pharmacological agents like propofol, opiods, ${ }^{14,15,16}$ clonidine, ${ }^{17}$ midazolam, ${ }^{18}$ and dexmedetomidine ${ }^{16,19,20}$ have been used prophylactically to reduce the incidence of emergence agitation.

Dexmedetomidine is a selective alpha- 2 adrenergic agonist with sympatholytic, analgesic and sedative properties. It does not produce respiratory depression as it doesn't act on the GABA receptors. In addition it has the unique property of rapid onset and short duration cooperative sedation. It is also anxiolytic and antisecretory. ${ }^{21}$ It has been used successfully to reduce EA in children ${ }^{22,23,24,25}$ and for weaning from ventilator in intensive care. ${ }^{26}$ It has been shown to reduce opioid consumption, pain intensity, stress response and thus improve quality of recovery after surgery. 19,27-29 The literature with respect to the effects of dexmedetomidine on reducing emergence agitation in adults is limited. In the present randomized, double blind, placebo-controlled study we hypothesized that intra-operative dexmedetomidine infusion would reduce emergence agitation in adults, undergoing nasal surgery.

\section{METHODS}

After obtaining clearance from the Institutional Ethical Committee, the present study was undertaken at Sambhram Medical College Hospitals, during the period June 2017 to May 2018. One hundred patients who were scheduled to undergo elective nasal surgeries requiring nasal packing under general anaesthesia were included in the study. The sample size was taken based on the convenience of the study.

\section{Inclusion Criteria}

1. Age 20-60 years.

2. American Society of Anesthesiologists (ASA) Grade I or II. ${ }^{9}$

3. Patients undergoing elective nasal surgeries under general anaesthesia and requiring nasal packing after surgery.

\section{Exclusion Criteria}

1. Known or suspected allergy to $\alpha_{2}$ adrenergic agonists.

2. Use of monoamine oxidase inhibitors, adrenergic blocking agents or clonidine.

3. Uncontrolled hypertension and Diabetes mellitus.

4. Heart block greater than first degree.

5. Cognitive impairment.

6. Chronic use of antipsychotic medications.

7. Kidney or liver disease.

8. Body mass index $\geq 30 \mathrm{Kg} / \mathrm{m}^{2}$.

9. Pregnancy.

Patients scheduled to undergo elective nasal surgery at Sambhram Medical College Hospital were assessed for eligibility. Those satisfying the inclusion criteria were randomly allocated into two groups by computer generated random number table.

\section{Group D}

Patients received dexmedetomidine infusion at a rate of 0.4 $\mathrm{mcg} / \mathrm{Kg} / \mathrm{hr}$. from the beginning of induction of anaesthesia until extubation.

\section{Group C}

Patients received volume matched normal saline infusion as placebo.

The study drug was prepared by an anaesthesiologist not involved in data collection. The investigator, attending 
anaesthesiologist and patients were blinded to group allocation. A detailed pre anaesthetic evaluation was done in all patients. Investigations were done according to ASA guidelines as appropriate for the age and the individual patient. All patients were pre-medicated with oral pantoprazole $40 \mathrm{mg}$ and oral ondansetron $4 \mathrm{mg}$ on the morning of surgery. Injection midazolam $0.02 \mathrm{mg} / \mathrm{Kg}$ I.V. was given $30 \mathrm{~min}$ prior to induction of anaesthesia to all patients.

Once the patient was shifted to the operation room, minimal mandatory monitoring consisting of electrocardiogram, non-invasive blood pressure and pulse oximetry were instituted. After preoxygenation for $3 \mathrm{~min}$, general anaesthesia was induced with fentanyl $2 \mathrm{mcg} / \mathrm{Kg}$ and propofol $2 \mathrm{mg} / \mathrm{Kg}$. Orotracheal intubation with appropriate sized ET tube was facilitated with atracurium $0.5 \mathrm{mg} / \mathrm{Kg}$. Anaesthesia was maintained with 1 MAC desflurane in $50 \%$ air/oxygen mixture. The attending anaesthesiologist was free to administer additional doses of fentanyl as he/she may feel appropriate. During the intraoperative course vitals were monitored. During the intra-operative course bradycardia (HR $<40 \mathrm{bpm}$ ) was treated with intravenous atropine $0.5 \mathrm{mg}$ and tachycardia (HR >110 bpm) was treated with intravenous esmolol in $10 \mathrm{mg}$ increments. Hypotension (MAP < $60 \mathrm{mmHg}$ ) was treated with intravenous ephedrine in $3 \mathrm{mg}$ increments. Paracetamol infusion of $1 \mathrm{gm}$ was given at end of surgery, during nasal packing in all patients. Upon completion of surgery throat pack was removed and thorough oral suctioning was done. Reversal agents (neostigmine $50 \mathrm{mcg} / \mathrm{Kg}$ and glycopyrrolate $10 \mathrm{mcg} / \mathrm{Kg}$ ) were given after confirming return of neuromuscular blockade using train-of-four peripheral nerve stimulation. Presence of $4^{\text {th }}$ twitch on train of four stimulation was used as an indicator for giving reversal agents. Following the administration of reversal agents desflurane was turned off (defined as 'time zero' in emergence process) in both groups and patients were ventilated with $100 \%$ oxygen. Patients were not disturbed except for continual verbal requests to open their eyes. All other stimuli in the form of repeated suctioning or touch were avoided. They were extubated once they began to breathe spontaneously with adequate tidal volume and were able to respond to verbal requests. After extubation study drug infusion was stopped.

Emergence is defined as the time interval from time zero to $2 \mathrm{~min}$ after extubation. During emergence the level of agitation was assessed by Ricker sedation-agitation scale and each patient's maximum agitation score was recorded.

\begin{tabular}{|c|c|c|}
\hline Score & Category & Description \\
\hline 7 & $\begin{array}{c}\text { Dangerous } \\
\text { agitation }\end{array}$ & $\begin{array}{c}\text { Pulling at endotracheal tube, trying to remove catheters, } \\
\text { climbing over bedrail, striking at staff, thrashing side-to-side }\end{array}$ \\
\hline 6 & $\begin{array}{c}\text { Very } \\
\text { agitated }\end{array}$ & $\begin{array}{c}\text { Does not calm despite frequent verbal reminding of limits, } \\
\text { requires physical restraints, biting endotracheal tube }\end{array}$ \\
\hline 5 & Agitated & $\begin{array}{c}\text { Anxious or mildly agitated, attempting to sit up, calms down on } \\
\text { verbal instructions }\end{array}$ \\
\hline 4 & $\begin{array}{c}\text { Calm, } \\
\text { cooperative }\end{array}$ & Calm, easily arousable, follows commands \\
\hline 3 & Sedated & $\begin{array}{c}\text { Difficult to arouse, awakens to verbal stimuli or gentle shaking } \\
\text { but drifts off again, follows simple commands }\end{array}$ \\
\hline 2 & $\begin{array}{c}\text { Very } \\
\text { sedated }\end{array}$ & $\begin{array}{c}\text { Arouses to physical stimuli but does not communicate or follow } \\
\text { commands, may move spontaneously }\end{array}$ \\
\hline 1 & Unarousable & $\begin{array}{c}\text { Minimal or no response to noxious stimuli, does not } \\
\text { communicate or follow commands }\end{array}$ \\
\hline \multicolumn{3}{|c|}{ Table 1. Ricker Sedation Agitation Scale } \\
\hline
\end{tabular}

Emergence agitation was defined as any score on the sedation-agitation scale equal to or more than 5. Dangerous agitation was defined as score equal to 7 . Patients who had emergence agitation were given injection fentanyl $0.5 \mathrm{mcg} / \mathrm{Kg}$ intravenously. If the agitation score persisted to be more than 5 after 2 min following fentanyl administration, injection propofol $0.5 \mathrm{mg} / \mathrm{Kg}$ I.V. was given. Along with the agitation score, the length of period from "time zero" to first verbal response and extubation were noted.

Heart rate, systolic, diastolic and mean arterial blood pressure were recorded before induction of anaesthesia, 10 min after start of surgery, 30 min after start of surgery, at the end of surgery, at extubation and 2 min after extubation. Desaturation, laryngospasm and any other complication during emergence, as well as residual sedation (sedationagitation score $\leq 3$ ) on arrival in post anaesthetic care unit were recorded. Patients were discharged from PACU when their Aldrete score was $\geq 9$.

\begin{tabular}{|c|c|c|}
\hline Criteria & Point Value \\
\hline \multirow{3}{*}{ Respiration } & Ability to cough and deep breath & 2 \\
& Dyspnoeic, shallow or limited breathing & 1 \\
& Apnoea & 0 \\
\hline \multirow{3}{*}{ Circulation } & Blood pressure $\pm 20 \mathrm{mmHg}$ of normal & 2 \\
& Blood pressure $\pm 20-50$ mmHg of normal & 1 \\
& Blood pressure more than $\pm 50 \mathrm{mmHg}$ of normal & 0 \\
\hline \multirow{3}{*}{ Consciousness } & Fully awake & 2 \\
& Arousable on calling & 1 \\
& Not responsive & 0 \\
\hline \multirow{3}{*}{ Oxygenation } & SpO2 $>$ 92 \% on room air & 2 \\
& Sp02 $>90 \%$ on oxygen & 1 \\
\hline \multirow{2}{*}{ Activity } & SpO2 $<90 \%$ on oxygen & 2 \\
& Moves all extremities & 1 \\
& Moves two extremities & 0 \\
\hline \multicolumn{2}{|c|}{ Table 2. Aldrete Score $\mathbf{1 2}$} \\
\hline
\end{tabular}

\section{Sample Size}

Kim et $a l,{ }^{13}$ in their study have observed that incidence of emergence agitation after nasal surgery is around 52\% in those not receiving dexmedetomidine infusion. The incidence of emergence agitation was reduced by $46 \%$ after nasal surgeries in adults following dexmedetomidine infusion. In the present study, expecting the similar results with 95\% confidence and $80 \%$ power and considering $24 \%$ minimum detectable difference, the study required a minimum of 50 subjects in each group.

\section{Statistics}

Descriptive and inferential statistical analyses were carried out in the present study. Results on continuous measurements are presented on Mean \pm SD (min-max) and results on categorical measurements are presented in Number (\%). Significance is assessed at $5 \%$ level of significance.

\section{The following Assumptions on Data were made}

1. Dependent variables should be normally distributed.

2. Samples drawn from the population should be random.

3. Cases of the samples should be independent.

Student $\mathrm{t}$ test (two tailed, independent) has been used to find the significance of study parameters on continuous scale between two groups (inter group analysis) on metric parameters. Chi-square/Fisher Exact test has been used to find the significance of study parameters on categorical scale between two or more groups. $\mathrm{p}<0.05$ was considered statistically significant. The Statistical software SPSS 15.0, was used for the analysis of the data and Microsoft word and Excel have been used to generate graphs, tables etc. 


\section{RESULTS}

In the present study to evaluate the efficacy of dexmedetomidine for prevention of emergence agitation in adults following nasal surgery under general anaesthesia, conducted Sambhram Medical College Hospital the following observations were made. Table $3 \mathrm{~A}$ and $3 \mathrm{~B}$ shows the age and gender distribution between two groups. The mean age for group C was $36.92 \pm 11.61$ and group D was $33.32 \pm 10.18$. There was no statistical significant difference between the two groups and were comparable with respect to age and sex.

\begin{tabular}{|c|c|c|c|c|}
\hline \multicolumn{5}{|c|}{ 3A. Age Distribution of Patients Studied } \\
\hline \multirow{2}{*}{ Age in Years } & \multicolumn{2}{|c|}{ Group C* $(n=50)$} & \multicolumn{2}{|c|}{ Group D* $(n=50)$} \\
\hline & No & $\%$ & No & $\%$ \\
\hline $20-30$ & 16 & 32.0 & 22 & 44.0 \\
\hline $31-40$ & 16 & 32.0 & 17 & 34.0 \\
\hline $41-50$ & 12 & 24.0 & 7 & 14.0 \\
\hline $51-60$ & 6 & 12.0 & 4 & 8.0 \\
\hline Mean \pm SD & \multicolumn{2}{|c|}{$36.92 \pm 11.61$} & \multicolumn{2}{|c|}{$33.32 \pm 10.18$} \\
\hline \multicolumn{5}{|c|}{ 3B. Gender Distribution of Patients Studied } \\
\hline \multirow{2}{*}{ Gender } & \multicolumn{2}{|c|}{ Group C* $(n=50)$} & \multicolumn{2}{|c|}{ Group D* $(n=50)$} \\
\hline & No & $\%$ & No & $\%$ \\
\hline Female & 9 & 18.0 & 11 & 22.0 \\
\hline Male & 41 & 82.0 & 39 & 78.0 \\
\hline \multicolumn{5}{|c|}{ 3C. Comparison of Weight, Height and BMI in the Two Groups of Patients Studied } \\
\hline Variables & \multicolumn{2}{|c|}{ Group C* $(n=50)$} & \multicolumn{2}{|c|}{ Group D* $(n=50)$} \\
\hline Weight (kg) & \multicolumn{2}{|c|}{$62.88 \pm 9.68$} & \multicolumn{2}{|c|}{$64.46 \pm 9.54$} \\
\hline Height $(\mathrm{cm})$ & \multicolumn{2}{|c|}{$164.36 \pm 7.51$} & \multicolumn{2}{|c|}{$165.46 \pm 8.05$} \\
\hline BMI $\left(\mathrm{Kg} / \mathrm{m}^{2}\right)$ & \multicolumn{2}{|c|}{$23.21 \pm 3.01$} & \multicolumn{2}{|c|}{$23.43 \pm 3.08$} \\
\hline \multicolumn{5}{|c|}{ Table 3. Demography } \\
\hline
\end{tabular}

Table 3C shows weight, height and BMI distribution of the patients in the two groups. The mean weight in group $\mathrm{C}$ and $\mathrm{D}$ were $62.88 \pm 9.68$ and $64.46 \pm 9.54$ respectively. The mean height in group C and D were 164.36 \pm 7.51 and $165.46 \pm 8.05$ respectively. The mean BMI in group $C$ and $D$ were $23.21 \pm 3.01$ and $23.43 \pm 3.08$ respectively. There was no significant difference in the weight, height and BMI of patients between the groups. Both the groups were similar with respect to weight, height and BMI distribution ( $p>0.05$ ). Table 4 A shows the duration of surgery among two groups. The mean duration of surgery between Group C and group D was 102.30 \pm 41.07 min and $93.04 \pm 40.06$ min respectively. There was no statistical significance. $(p=0.257)$. Table $4 B$ shows the distribution of various surgeries among the two groups and distribution was matched between two study groups $(\mathrm{p}=$ 0.167)

\begin{tabular}{|c|c|c|c|c|}
\hline \multicolumn{5}{|c|}{ Comparison for Duration of Surgery } \\
\hline \multirow{2}{*}{$\begin{array}{c}\text { Duration of } \\
\text { Surgery (min) }\end{array}$} & \multicolumn{2}{|c|}{ Group C* $(n=50)$} & \multicolumn{2}{|c|}{ Group D* $(n=50)$} \\
\hline & No & $\%$ & No & $\%$ \\
\hline$<60$ & 7 & 14.0 & 10 & 20.0 \\
\hline $60-120$ & 28 & 56.0 & 27 & 58.0 \\
\hline$>120$ & 15 & 30.0 & 13 & 26.0 \\
\hline $\begin{array}{c}\text { Mean } \pm \text { SD }(* P> \\
0.05)\end{array}$ & \multicolumn{2}{|c|}{$102.30 \pm 41.07$} & \multicolumn{2}{|c|}{$93.04 \pm 40.06$} \\
\hline \multicolumn{5}{|c|}{ Types of Surgery in Study Groups } \\
\hline \multirow{2}{*}{ Surgery } & \multicolumn{2}{|c|}{ Group C* $(n=50)$} & \multicolumn{2}{|c|}{ Group D* $(n=50)$} \\
\hline & No & $\%$ & No & $\%$ \\
\hline FESS & 20 & 40.0 & 27 & 54.0 \\
\hline Septoplasty & 23 & 46.0 & 16 & 32.0 \\
\hline SMD + Septoplasty & 7 & 14.0 & 4 & 8.0 \\
\hline Turbinectomy & 0 & 0.0 & 2 & 4.0 \\
\hline Polypectomy & 0 & 0.0 & 1 & 2.0 \\
\hline \multicolumn{5}{|c|}{$\begin{array}{c}\text { Table 4. Comparison for Duration of Surgery and } \\
\text { Types of Surgeries in the Study Groups }\end{array}$} \\
\hline
\end{tabular}

Agitation score: It was noted that 29 patients (58\%) in group $\mathrm{C}$ and 2 patients (4\%) in group D had sedation-agitation score $\geq 5$ and were deemed to have emergence agitation as per the definition employed for this study. Agitation score was compared between two groups and was found to be statistically significant with $\mathrm{p}<0.001$ this was represented in Table 9. None of the patients in both groups were severely agitated (score=7). Of the 29 patients who were deemed to have emergence agitation in group C, 19 patients had a score of 5 and 10 patients had a score of 6 . All the 29 patients were administered fentanyl for treating agitation. None of these patients required propofol, as their agitation resolved within 2 min following fentanyl administration. Of the 2 patients who had emergence agitation in group D, both had a score of 5 and EA terminated with administration of fentanyl.

\begin{tabular}{|c|c|c|c|c|}
\hline \multirow{2}{*}{ Agitation Score } & \multicolumn{2}{|c|}{ Group C* $(\mathbf{n}=\mathbf{5 0})$} & \multicolumn{2}{c|}{ Group D* $(\mathbf{n = 5 0})$} \\
\cline { 2 - 5 } & No & $\mathbf{\%}$ & No & $\%$ \\
\hline$\leq 4$ & 21 & 42.0 & 48 & 96.0 \\
\hline$\geq 5$ & 29 & 58.0 & 2 & 4.0 \\
\hline \multicolumn{3}{|c|}{ Table 5. Agitation-Score in the Two Groups } \\
\hline${ }^{*} \mathrm{p}<0.005$
\end{tabular}

Table 6A shows the comparison of heart rate between the two groups at various stages of surgery. The basal heart rate was comparable between the two groups. Throughout the intraoperative period, at extubation and $2 \mathrm{~min}$ after extubation the $H R$ was significantly lower in the dexmedetomidine group (group D) compared to saline group (group C)

\begin{tabular}{|c|c|c|}
\hline \multicolumn{3}{|c|}{ 6A. Comparison of Heart Rate between Two Groups } \\
\hline Heart Rate (bpm) & Group C $(n=50)$ & Group D (n=50) \\
\hline Baseline & $80.20 \pm 16.87$ & $79.96 \pm 14.97$ \\
\hline $10 \mathrm{~min}^{*}$ & $77.58 \pm 14.50$ & $70.88 \pm 10.77$ \\
\hline $30 \mathrm{~min}^{*}$ & $75.82 \pm 13.55$ & $68.10 \pm 8.81$ \\
\hline End of surgery* & $85.68 \pm 13.20$ & $75.32 \pm 10.69$ \\
\hline Extubation* & $103.32 \pm 17.54$ & $84.14 \pm 12.71$ \\
\hline Extubation- 2 min* & $100.42 \pm 15.21$ & $80.14 \pm 10.47$ \\
\hline \multicolumn{3}{|c|}{${ }^{*} \mathrm{p}<0.05$ Data presented as mean $\pm \mathrm{SD}$} \\
\hline \multicolumn{3}{|c|}{ 6B. Comparison of MAP between the Two Groups } \\
\hline MAP (mmHg) & Group C $(n=50)$ & Group D (n=50) \\
\hline Baseline & $92.58 \pm 9.45$ & $97.80 \pm 12.87$ \\
\hline $10 \mathrm{~min}$ & $70.32 \pm 10.92$ & $68.92 \pm 7.59$ \\
\hline $30 \mathrm{~min}^{*}$ & $73.86 \pm 9.44$ & $69.86 \pm 8.81$ \\
\hline End of surgery* & $80.56 \pm 11.44$ & $74.40 \pm 12.11$ \\
\hline Extubation* & $92.38 \pm 12.92$ & $85.82 \pm 12.62$ \\
\hline Extubation $-2 \mathrm{~min}$ & $94.42 \pm 12.29$ & $90.02 \pm 11.91$ \\
\hline \multicolumn{3}{|c|}{${ }^{*} \mathrm{p}<0.05$ Data presented as mean $\pm \mathrm{SD}$} \\
\hline \multicolumn{3}{|c|}{ ES -- End of surgery, EXT - Extubation, EXT 2 - 2 minutes after Extubation } \\
\hline
\end{tabular}

It was found that dexmedetomidine group had lower heart rate compared to saline group as shown above. Table 7B shows the distribution of MAP between the two groups. The MAP was comparable at baseline and at $10 \mathrm{~min}$ after surgery, where as it was significantly lower in group D compared to group $C$ at 30 min after start of surgery at end of surgery and at extubation $(\mathrm{p}<0.05)$. At 2 min after extubation the MAP was comparable between two groups.

\section{DISCUSSION}

Emergence agitation is a well described, complex, clinical phenomenon of multifactorial aetiology seen following emergence from general anaesthesia. Though it is most often seen in children and elderly,2,3 it can affect all age groups. Emergence agitation can increase healthcare costs due to its morbidity, longer PACU stay, human resources required and the pharmaceuticals used to treat it. ${ }^{12}$ Although clinical studies investigating EA continue to be published, this field continues 
to face significant limitations due to lack of universally accepted definition and gold standard assessment tool. Thus comparing outcomes across different studies remains problematic and clinical management questionable. Studies have shown that among the various surgeries, otolaryngologic surgeries are associated with a higher incidence of EA.9-11 Various pharmacological agents have been used prophylactically to reduce EA following general anaesthesia with differing success rate. $13-18,20,23$ The present study was conducted in 100 adults aged 20-60 years, ASA 1-2, undergoing nasal surgeries under general anaesthesia and requiring nasal packing for at least $24 \mathrm{hrs}$ after surgery. An infusion of dexmedetomidine at $0.4 \mathrm{mcg} / \mathrm{Kg} / \mathrm{hr}$ from the beginning of induction till extubation was compared with a placebo (saline infusion) to evaluate its efficacy in reducing EA.

Premedication: All patients in the present study received pantoprazole, ondansetron and midazolam as premedication as per the usual institutional protocol prior to surgery. The role of benzodiazepine premedication on EA is controversial. Some studies reported that the use of benzodiazepine premedication predisposes to EA, while others have found it to be protective. Preoperative anxiety is also a known risk factor for EA. ${ }^{12}$ Benzodiazepines are most commonly used to reduce anxiety preoperatively. In view of the above reasons we used midazolam for premedication in all patients as per the institutional practice. Dexmedetomidine is one among the various pharmacological agents employed prophylactically for EA.13,20,23 It has been used as a single bolus injection, continuous infusion or bolus followed by continuous infusion in various doses for prevention of EA with variable success. ${ }^{13,20,23,}$ The appropriate dose in which it is effective in preventing EA is yet to be published in literature. In the present study we used dexmedetomidine as a continuous infusion at $0.4 \mathrm{mcg} / \mathrm{Kg} / \mathrm{hr}$ as employed by Kim S Y et al. ${ }^{13}$

There is no "gold standard" assessment tool available for evaluation of EA. The various scales that have been used to evaluate agitation are; Ricker agitation-sedation scale, Richmond sedation agitation scale, the motor activity assessment scale and the modified New Sheffield sedation scale. Studies have shown that both the Ricker and Richmond scales have excellent inter-rater reliability. All these scales were created for adults in the ICU and none has so far been established solely for use in PACU. However, we feel patients admitted to the PACU are comparable to those admitted to the ICU and these scales are easy to use and give a precise evaluation of agitation. In the present study we employed the Ricker agitation-sedation scale for evaluation of EA.

\section{Emergence Agitation}

The incidence of EA in the present study was $58 \%$ in the control group (group C) whereas it was $4 \%$ in the dexmedetomidine (group D). Emergence agitation is especially common after ENT surgeries ${ }^{9-11}$ and this higher incidence is attributed to sense of suffocation due to nasal packing. ${ }^{9}$ The incidence of EA for nasal surgeries reported in literature varies from $22.2 \%$ to $55.4 \% .^{10}$ The incidence of EA in the present study was $58 \%$ and is similar to those seen in the studies conducted by Kim SY et al ${ }^{13}(52 \%)$ and Yu D et al (55.4\%). ${ }^{10} \mathrm{Kim} \mathrm{H}-\mathrm{Y}$ et al in their study reported the incidence of EA as $22.2 \%$. Most of their patients received total intravenous anaesthesia with propofol and remifentanil. Total intravenous anaesthesia is known to be protective against EA, ${ }^{10,12}$ hence this may be one of the reason for observing a lower incidence in this study compared to present one.

In the present study patients who were expected to have a higher risk of EA, i.e., those requiring nasal packing, use of tracheal tube, benzodiazepine premedication and inhalational agents, were included. Hence as expected, in group $C$ the incidence of EA was higher (58\%) similar to the previously reported results.9,13 Dexmedetomidine is known to produce sedation and analgesia without respiratory depression. ${ }^{21}$ Hence, it has been used for prevention of EA. Intraoperative dexmedetomidine has been seen to reduce EA in children by $57-70 \%$ compared with control groups ${ }^{22-25}$ and by $46 \%$ in a study conducted in adults. ${ }^{13}$ In the present study the use of intraoperative dexmedetomidine infusion significantly decreased EA from 58\% (group C) to $4 \%$ (group D) [p < 0.05 ], a $54 \%$ reduction similar to the result reported by Kim S-Y et al. ${ }^{13}$ The exact mechanism as how dexmedetomidine prevents EA is not clear. Though EA is a well-recognized phenomenon, its pathophysiological mechanism is not well understood and various mechanisms have been postulated. Among the various mechanisms, locus coeruleus is thought to be an important area involved in EA. This is an area within the pons that is involved in the physiologic response to stress.

\section{Time to Verbal Response and Extubation}

The time to verbal response was significantly longer in group D than in group C (group D v/s group C, $6.74 \pm 2.13 \mathrm{~min} \mathrm{v} / \mathrm{s}$ $5.78 \pm 1.91 \mathrm{~min}, \mathrm{p}<0.05$ ). The time to extubation was not significantly different between the two groups (group D v/s group C, $8.06 \pm 2.14 \mathrm{~min} \mathrm{v/s} 7.42 \pm 2.24 \mathrm{~min}, \mathrm{p}>0.05$ ). These results were similar to that seen by Kim SY et al. ${ }^{13}$ The time to eye opening to verbal stimuli has been found to be longer when compared to placebo by Erdil $\mathrm{F}$ et $\mathrm{al}^{25}$ and Guler $\mathrm{G}$ et al ${ }^{24}$ in their study. The time to extubation was not significantly different in dexmedetomidine group $(0.4 \mathrm{mcg} / \mathrm{Kg} / \mathrm{hr}$.) when compared to a saline group by Tutangullian et al.27

\section{Intraoperative Fentanyl Requirement}

The number of patients who required intraoperative fentanyl were 5 and 21 in group D and C respectively. Inter quartile range of total fentanyl used in group D was $20-30 \mathrm{mcg}$ whereas the inter quartile range was $20-42.5 \mathrm{mcg}$ in group C. Dexmedetomidine is known to decrease the perioperative requirement of opioids and has an opioid-sparing action. The present study also showed that the number of patients requiring extra fentanyl doses intraoperatively were less in those who received dexmedetomidine infusion. This was similar to the findings seen by Erdil et al ${ }^{25}$ and Gurbet A et al. ${ }^{24}$

\section{Haemodynamic Effects}

The HR throughout the intraoperative period, at extubation and 2 min after extubation was significantly lower in group D compared to group $\mathrm{C}(\mathrm{p}<0.05)$. This was similar to that seen by Kim S-Y et al. ${ }^{13}$ Dexmedetomidine is known to decrease heart rate by central sympatholysis and thus explains lower heart rates in patients receiving dexmedetomidine. The MAP was significantly lower in group D compared to Group C at 30 min after start of surgery, at end of surgery and at extubation $(p<0.05)$. This is similar to that seen by Kim SY et al.13 The property of dexmedetomidine to decrease blood pressure 
explains the lower MAP in group D. However, the MAP at 10 min after start of surgery and 2 min after extubation were similar between the two groups. Dexmedetomidine is usually administered as an initial loading dose followed by an infusion. In the present study we did not use a bolus dose and began as an infusion at $0.4 \mathrm{mcg} / \mathrm{Kg} / \mathrm{hr}$. Because hypertension is common after administration of the loading dose of dexmedetomidine, we administered a continuous infusion without a loading dose which is also found to be effective in reducing emergence agitation. ${ }^{13,26}$ Thus it may require a longer duration for dexmedetomidine to decrease blood pressure when administered as an infusion without a loading dose. Two minutes after extubation the MAP in both groups were similar, probably because at extubation dexmedetomidine infusion was turned off and awakening of patient may contribute to an increase in MAP.

\section{Duration of PACU Stay}

The duration of PACU stay was similar between the two groups (group D v/s group C, $7.06 \pm 3.05 \mathrm{~min} v / \mathrm{s} 7.96 \pm 2.22 \mathrm{~min}$, $p>0.05)$. Similar to the present study, dexmedetomidine in the dose of $0.4 \mathrm{mcg} / \mathrm{Kg} / \mathrm{hr}$. is not known to increase the length of the PACU stay. $13,20,27$

\section{Adverse Effects}

The present study was not powered to draw statistical inferences with respect to any adverse effects. Dexmedetomidine is known to cause bradycardia, hypotension and hypertension. None of the patients in both the groups had bradycardia. Hypotension (defined as MAP < $60 \mathrm{mmHg}$ ) was noted in 17 (34\%) patients in group C and 21 (42\%) patients in group D and was similar. Tachycardia (defined as $\mathrm{HR}>110$ ) was noted in 3 patients in group $\mathrm{C}$ and required intravenous esmolol. None of the patients in group $D$ had tachycardia. None of the patients in both groups had desaturation (SpO2 < 90\%), laryngospasm. One patient in group D had residual sedation (sedation score $\leq 3$ ).

\section{CONCLUSIONS}

Dexmedetomidine as an infusion of $0.4 \mathrm{mcg} / \mathrm{Kg} / \mathrm{hr}$., from induction till extubation reduces emergence agitation in adults undergoing nasal surgery under desflurane general anaesthesia.

\section{ACKNOWLEDGEMENT}

Authors thank the patients who participated in the study, and the staff of the operating theatres for their assistance and cooperation.

\section{REFERENCES}

[1] O'Brien D. Acute postoperative delirium: definition, incidence, recognition and interventions. J Perianesth Nurs 2002;17(6):384-92.
[2] Scott GM, Gold JI. Emergence delirium: a re-emerging interest. Seminars in Anesthesia, Perioperative Medicine and Pain 2006;25(3):100-4.

[3] Hudek K. Emergence delirium: a nursing perspective. AORN J 2009;89(3):509-16, quiz 517-9.

[4] Radtke FM, Frank M, Hagemann L, et al. Risk factors for inadequate emergence after anesthesia: emergence delirium and hypoactive emergence. Minerva Anestesiol 2010;76(6):394-403.

[5] Burns SM. Delirium during emergence from anaesthesia: a case study. Crit Care Nurse 2003;23(1):66-9.

[6] Xara D, Silva A, Mendonca J, et al. Inadequate emergence after anaesthesia: emergence delirium and hypoactive emergence in the Postanesthesia Care Unit. J Clin Anesth 2013;25(6):439-46.

[7] Dodds C, Allison J. Postoperative cognitive deficit in the elderly surgical patient. Br J Anaesth 1998;81(3):449-62.

[8] O'keeffe ST, Ni Chonchubhair A. Postoperative delirium in the elderly. Br J Anaesth 1994;73(5):673-87.

[9] Eckenhoff JE, Kneale DH, Dripps RD. The incidence and etiology of postanesthetic excitement. A clinical survey. Anesthesiology 1961;22:667-73.

[10] Yu D, Chai W, Sun X, et al. Emergence agitation in adults: risk factors in 2,000 patients. Can J Anaesth 2010;57(9):843-8.

[11] Lewis TV, Malviya S, Tait AR. A prospective cohort study of emergence agitation in the pediatric postanaesthetic care unit. Anesth Analg 2003;96(6):1625-30.

[12] Lepouse C, Lautner CA, Liu L, et al. Emergence delirium in adults in the post-anaesthesia care unit. Br J Anaesth 2006;96(6):747-53.

[13] Kim SY, Kim JM, Lee JH, et al. Efficacy of intraoperative dexmedetomidine infusion on emergence agitation and quality of recovery after nasal surgery. Br J Anaesth 2013;111(2):222-8.

[14] Cohen IT, Hannallah RS, Hummer KA. The incidence of emergence agitation associated with desflurane anesthesia in children is reduced by fentanyl. Anesth Analg 2001;93(1):88-91.

[15] Galinkin JL, Fazi LM, Cuy RM, et al. Use of intranasal fentanyl in children undergoing myringotomy and tube placement during halothane and sevoflurane anesthesia. Anesthesiology 2000;93(6):1378-83.

[16] Finkel JC, Cohen IT, Hannallah RS, et al. The effect of intranasal fentanyl on the emergence characteristics after sevoflurane anesthesia in children undergoing surgery for bilateral myringotomy tube placement. Anesth Analg 2001;92(5):1164-8.

[17] Kulka PJ, Bressem M, Tryba M. Clonidine prevents sevoflurane-induced agitation in children. Anesth Analg 2001;93(2):335-8.

[18] Ko YP, Huang CJ, Hung YC, et al. Premedication with lowdose oral midazolam reduces the incidence and severity of emergence agitation in pediatric patients following sevoflurane anesthesia. Acta Anaesthesiol Sin 2001;39(4):169-77.

[19] Gurbet A, Mongol EB, Turker G, et al. Intraoperative infusion of dexmedetomidine reduces perioperative analgesic requirements. Can J Anaesth 2006;53(7):64652 . 
[20] Ibacache ME, Munoz HR, Brandes V, et al. Single-dose dexmedetomidine reduces agitation sevoflurane anaesthesia in children. Anesth Analg 2004;98(1):60-3.

[21] Gerlach TA, Dasta JF. Dexmedetomidine: an updated review. Ann Pharmacother 2007;41(2):245-52.

[22] Patel A, Davidson M, Tran MCJ, et al. Dexmedetomidine infusion for analgesia and prevention of emergence agitation in children with obstructive sleep apnea syndrome undergoing tonsillectomy and adenoidectomy. Anesth Analg 2010;111(4):1004-10.

[23] Shukry M, Clyde MC, Kalarickal PL, et al. Does dexmedetomidine prevent emergence agitation after sevoflurane- based anaesthesia? Paediatr Anaesth 2005;15(12):1098-104.

[24] Guler G, Akin A, Tosun Z, et al. Single dose dexmedetomidine reduces agitation and provides smooth extubation after pediatric adenotonsillectomy. Pediatr Anaesth 2005;15(9):762-6.

[25] Erdil R, Demirbilek S, Begec Z, et al. The effects of dexmedetomidine and fentanyl on emergence characteristics after adenoidectomy in children. Anaesth Intensive Care 2009;37(4):571-6.
[26] Shehabi Y, Nakae H, Hammond N, et al. The effect of dexmedetomidine on agitation during weaning of mechanical ventilation in critically ill patients. Anaesth Intensive Care 2010;38(1):82-90.

[27] Tufanogullari B, White PF, Peixoto MP, et al. Dexmedetomidine infusion during laparoscopic bariatric surgery: The effect on recovery outcome variables. Anesth Analg 2008;106(6):1741-8.

[28] Bekker A, Haile M, Kline R, et al. The effect of intraoperative infusion of dexmedetomidine on quality of recovery after major spinal surgery. J Neurosurg Anesthesiol 2013;25(1):16-24.

[29] Blaudszun G, Lysakowski C, Elia N, et al. Effect of perioperative systemic $\alpha 2$ agonists on perioperative morphine consumption and pain intensity: systemic review and meta-analysis of randomized controlled trials. Anesthesiology 2012;116(6):1312-22. 